\title{
Renal Function Trajectory Is More Important than Chronic Kidney Disease Stage for Managing Patients with Chronic Kidney Disease
}

\author{
Steven J. Rosansky \\ WJB Dorn Veteran's Hospital, Columbia, S.C., USA
}

\author{
Key Words \\ Chronic kidney disease $\cdot$ Creatinine clearance $\cdot$ Diabetes \\ mellitus $\cdot$ End-stage renal disease $\cdot$ Hemodialysis $\cdot$ Kidney \\ failure $\cdot$ Proteinuria
}

\begin{abstract}
Management of patients with chronic kidney disease (CKD) emphasizes a current level of function as calculated from the modification of diet in renal disease glomerulofiltration rate equations (eGFR) and proteinuria for staging of CKD. Change in a patient's eGFR over time (renal function trajectory) is an additional and potentially more important consideration in deciding which patients will progress to the point where they will require renal replacement therapy (RRT). Many patients with CKD 3-5 have stable renal function for years. Proteinuria/albuminuria is a primary determinant of renal trajectory which may be slowed by medications that decrease proteinuria and/or aggressively lower blood pressure. A renal trajectory of $>3 \mathrm{ml} / \mathrm{min} / 1.73 \mathrm{~m}^{2} /$ year may relate to a need for closer renal follow-up and increased morbidity and mortality. Additional CKD population-based studies need to examine the relationship of renal trajectory to: baseline renal function; acute kidney injury episodes; age, race, sex and primary etiologies of renal disease; blood pressure control and therapies; dietary protein intake; blood glucose control in diabetics and the competitive risk of death versus the re-
\end{abstract}

quirement for renal replacement therapy. In the elderly CKD 4 population with significant comorbidities and slow decline in renal function, the likelihood of death prior to the need for RRT should be considered before placing AV access for dialysis. Prediction models of renal progression must account for the competitive risk of death as well as stable or improved renal function to be clinically useful.

Copyright $\odot 2012$ S. Karger AG, Basel

Guideline recommendations for the management of patients with chronic kidney disease (CKD) are generally based on severity of reduction in glomerulofiltration rate, as measured by the modification of renal disease (MDRD) four variable equations (eGFR) and level of proteinuria. Many studies have related the albuminuria component of urine protein excretion to outcomes. Albuminuria has been measured by urine albumin/creatinine ratios. Multiple first morning voided albumin/creatinine samples may be the most accurate way of determining a patient's baseline albuminuria [1]. Dipstick proteinuria, which measures total urine proteins and dipstick microalbuminuria, has also been shown to be predictive of CKD patient outcomes [1]. Variability of urine concentration may result in marked differences in urine dipstick results.

Several studies have demonstrated how different serum creatinine-based formulae for measurement of renal

\section{KARGER}

Fax +41613061234

E-Mail karger@karger.ch

www.karger.com
(C) 2012 S. Karger AG, Basel

0250-8095/12/0361-0001\$38.00/0

Accessible online at:

www.karger.com/ajn
Steven J. Rosansky, MD

526 N. Trenholm Rd

Columbia, SC 29206 (USA)

Tel. +1 8037389458

E-Mail sjrcra@yahoo.com 
function can give different CKD staging relative to the more accurate radioisotope measures of GFR [2]. Cystatin $\mathrm{C}$ has also been used to determine GFR and may be more accurate than serum creatinine based measures especially in patients with CKD stage 2/3 (GFR 30-89 ml/ $\mathrm{min} / 1.73 \mathrm{~m}^{2}$ ) [3]. CKD staging does not consider a potentially more important element in patient management, change in renal function over time, in $\mathrm{ml} / \mathrm{min} / 1.73 \mathrm{~m}^{2}$, which we will call 'renal trajectory'. Mitch and Walser [4] presented one of the first attempts to examine renal trajectory and concluded that one over serum creatinine followed a linear pattern in their small cohort followed over 5 years. To date, most studies looking at outcomes related to renal disease have not used renal trajectory as an end point. Most have used either a doubling of serum creatinine or time to initiation of renal replacement therapy (RRT). The latter is a very subjective assessment of trajectory, while doubling of serum creatinine is an objective measure but it does not consider the myriad issues related to trajectory. Renal function staging, acute kidney injury episodes (AKI) and renal trajectory all are predictive of patient survival [5-8]. The relative importance of each of these to CKD patient morbidity and mortality has not been examined.

To date, a review of patterns of renal function trajectory, factors that influence trajectory and use of renal trajectory in CKD patient management has not been published. Much of the literature on renal function decline assumes a linear pattern of progression. More recently, it has become apparent that patients with similar severity of kidney disease (as defined by CKD classification) can follow different trajectories. Some patients may experience rapid loss of renal function leading to end-stage renal failure (ESRD) and dialysis. Others may exhibit stable renal function over many years. Superimposed on chronic trajectories, patients can experience short-term fluctuations in kidney function in both the inpatient and outpatient setting, including episodes of AKI. Renal trajectory may change with drug therapy which may reverse the loss of renal function. As well, renal trajectory may impact treatment decisions like frequency of follow-up and preparation for RRT.

This review will examine the literature on renal function trajectory and highlight the methods used to measure renal function change over time; the patterns of renal function change; the factors that affect renal trajectory, including AKI episodes; use of renal trajectory in the management of patients with $\mathrm{CKD}$, and suggestions for future research.

\section{Measuring Renal Function Trajectory}

The first issue concerning measurement of renal trajectory is the method of creatinine determination. Recently, there has been an attempt to standardize this serum creatinine determination. For eGFR less than $60 \mathrm{ml} /$ $\mathrm{min} / 1.73 \mathrm{~m}^{2}$, eGFR may have acceptable reliability without recalibration to a standardized creatinine methodology [9]. Once serum creatinine has been determined, the commonest method used to measure renal function and renal trajectory utilizes MDRD eGFR. This equation accounts for the average loss of muscle over time with age and does not account for unusual body habitus or diet [10]. The equation is less accurate at higher levels of eGFR and recent publications have questioned its validity for eGFR less than $30 \mathrm{ml} / \mathrm{min} / 1.73 \mathrm{~m}^{2}$ [11, 12], where progressive muscle loss with renal disease progression may give falsely high eGFR. More recently, a revised version of the eGFR equation has been used (CKD-EPI equation) which may give a more accurate determination of GFR in patients with eGFR over $60 \mathrm{ml} / \mathrm{min} / 1.73 \mathrm{~m}^{2}$ [13]. In studies that examined the relative accuracy of MDRD eGFR, those patients with lower lean body mass had the greatest difference between radioisotope GFR and MDRD eGFR $[14,15]$.

Although serum creatinine and GFR determinations are clinically important, it may be more important to determine a patient's renal trajectory, assuming stable diet and muscle mass. Beyond these two factors, several methodological issues must be considered. In short-term studies rates of decline may reflect regression to the mean [16]. Baseline eGFR may vary if determined over 3 months, the interval currently used to define a patient's stage of CKD, versus 6,9 or 12 months, with the maximum number of data points resulting in the smallest variance of change over time [17].

Recent publications have used the slope-based least squares method to determine the best fit line for the longitudinal serum creatinine data points. Although eGFR slope may underestimate slope using iothalamate-based creatinine clearance [18], Fontseré et al. [19] found that in diabetic patients with CKD 2/3, MDRD eGFR was a better predictor of iothalamate GFR than 24-hour urine creatinine clearance. In the MDRD study and the AfricanAmerican study of kidney disease and hypertension (AASK), the slope-based method using eGFR underestimated the iothalamate-determined measured GFR [20]. Nevertheless, agreement between measured GFR and eGFR slope-based outcomes in the AASK study was relatively high $(R=0.93)[21]$. As well, the within patient vari- 
ability over time of eGFR on the basis of serum creatinine was slightly smaller than the within patient variability of radioisotope GFR. Thus, one may be able to estimate changes in renal function over time with serum creatinine-based methods.

One must be cautioned that the difference between measured (using iothalamate clearance) GFR versus eGFR slope can have profound clinical implications [22]. For example if the difference between the two slopes is $1 \mathrm{ml} / \mathrm{min} /$ year, the time to planned dialysis start can vary by many years [20]. In addition to the absolute change in renal function over time, Clark et al. [23] utilized percent annual change in eGFR to describe renal trajectory. The benefit of this method versus the more widely used absolute change per year has not been studied.

Although a regression line (slope) fitted to all of a patient's creatinine data points is the preferred method of measuring renal trajectory, a simple method used in some population studies of renal trajectory is a patient's initial available eGFR and latest available eGFR divided by years of observation to get change in eGFR in $\mathrm{ml} / \mathrm{min} / 1.73 \mathrm{~m}^{2} /$ year, which we will call 'basic renal trajectory' (BT). Alternatively, use of the mean values of the patient's first year of outpatient creatinine data points and most recent year's data points may decrease the variance of the result. The latter two methods, with an understanding of their limitations, may be a starting point in application of renal trajectory to clinical management.

\section{Patterns of Renal Function Trajectory}

Several questions arise when we examine renal trajectory patterns. Is a linear decline over time the commonest trajectory? How often does renal function remain stable for extended periods? How often do we see an increase of eGFR over time? Does the baseline renal function relate to trajectory? Does renal function decline at a more rapid rate as patients get to lower levels of renal function? How does an AKI episode affect renal trajectory?

The frequency of linear versus other patterns of decline over time has not been established. It has become clear that, even in patients with stage 4 or 5 CKD, a significant portion of these patients may have stable renal function. Levin et al., in a CKD 4/5 referral population found stable renal function in $37 \%$ of these patients after 2 years of follow-up [24]. Eriksen and Ingebretsen [25], in a population of patients average age 75 followed for 10 years with a baseline eGFR of $25-55 \mathrm{ml} / \mathrm{min} / 1.73 \mathrm{~m}^{2}$, found that $27 \%$ had no decline in eGFR. A stable trajec-

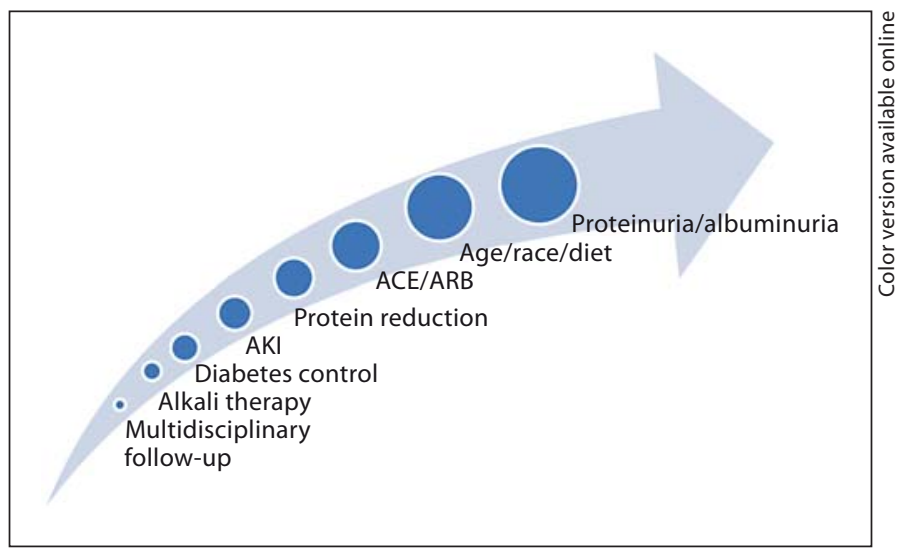

Fig. 1. Factors affecting renal function trajectory.

tory may be dependent on a patient's type of underlying renal disease, with proteinuric patients with glomerular disease having a more rapid trajectory than those with interstitial renal disease [26].

In the MDRD study, a patient's trajectory was not influenced by the baseline eGFR, and 15\% of the MDRD patients had an increase in eGFR [27]. Recently, Perkins et al. [28] demonstrated that increasing eGFR over time not only occurs, but may be associated with increased mortality risk.

\section{Factors Affecting Trajectory}

Although there is limited information regarding measurement of renal trajectory and patterns of renal trajectory, the following summarizes some of the extensive literature on factors that affect trajectory (fig. 1).

Age

Lindeman et al. [29] reported that the rate of decline of inulin or creatinine clearance increased as patients aged. This is in contrast to recent studies that report a slower decline in renal function with increasing age in patients with CKD [30-32]. O'Hare et al. [31], studying 11,290 veteran patients with an average eGFR of 17.7, found that older age was associated with slower decline in eGFR, in $\mathrm{ml} /$ $\mathrm{min} / 1.73 \mathrm{~m}^{2} /$ year, of $3.4,1.9$ and 1.3 , for age groups $65-74$, 75-84 and 85 and older, respectively. The discrepancy in results between O'Hare et al. and Lindeman et al. may in part be due to recent more aggressive blood pressure lowering and use of blood pressure medications that can decrease GFR loss. Also, one could argue that some of this 
difference found by O'Hare and coworkers in renal trajectory with older age is related to the fact that with age muscle mass decreases (sarcopenia) and that any examination of trajectory has to include patients who die who may well have a faster decline in renal function.

Sex

The rate of decline of renal function was reported to be faster in males than females [32-35], with the exception of postmenopausal women [36].

\section{Albuminuria/Proteinuria}

Albuminuria may be the most important predictor of renal function loss. There is a graded effect of albuminuria level on renal function decline independent of baseline renal function [37]. Lower level of renal function and level of albuminuria independently predicted a more rapid decline in eGFR using the basic trajectory (BT) method described above [38]. Stage 3 CKD patients who do not have albuminuria may have a slower BT than patients with stage 1 or 2 CKD and albuminuria [38].

Hallan et al. [1] studied a large Norwegian population over 10 years and noted that after accounting for albuminuria level, other factors were no longer predictive of renal function decline. In a Japanese cohort followed for 10 years, proteinuric patients had double the rate of renal function decline versus nonproteinuric patients [34]. In a large Canadian cohort, proteinuria was associated with more rapid renal function decline at every level of starting renal function [39]. In the AASK trial, after adjusting for baseline proteinuria, starting level of eGFR was not predictive of the decline in renal function over 3-6 years of follow-up [40]. In the Reduction of Endpoints in NIDDM with the Angiotensin II Antagonist Losartan (RENAAL) trial, proteinuria level was the most important predictor variable of progression in patients with type 2 diabetes and nephropathy [41].

\section{Race}

Although blacks have a much higher incidence of ESRD, the data relating the rate of decline in renal function according to race may vary by starting level of renal function. In a recent study by Peralta et al. [42], blacks had a more rapid rate of decline from normal renal function than whites. Nevertheless, in a systematic review of the literature, Barbour et al. [43] were unable to find differences in the rate of renal progression in blacks versus whites with established CKD. Disparities of income and blood pressure control can contribute to faster progression to ESRD in both blacks and whites [44]. The in- creased prevalence of proteinuria in African Americans may contribute to faster decline in eGFR, but after adjustment for proteinuria, eGFR, diagnoses hypertension and diabetes, as well as family income and educational status, there was no racial disparity in predicting ESRD for blacks compared to whites [45].

\section{Diet}

The MDRD study for the overall group showed no benefit of low-protein diet on renal progression. In patients with advanced CKD, low- and very-low-protein diets were used. The short- and long-term study results showed no benefit, and possible harm, of very-low-protein diet [46]. In the prevention of renal and vascular endstage disease (PREVEND) community cohort, there was no relationship between dietary protein intake and change in renal function [47].

\section{Smoking}

A report on the Nord-Tronndelag Health Study (HUNT) 2 population found smoking was associated with more rapid eGFR decline and a 3-4 times higher risk of ESRD versus nonsmokers [48]. This risk was decreased with smoking cessation.

\section{Hypertension Control}

Rosansky et al. [49], in a VA population without urinalysis or serum creatinine evidence of CKD, found that time-averaged clinic longitudinal blood pressure data predicted renal function decline in both hypertensive and normotensive patients. Several trials were designed with the hope that more aggressive blood pressure control could slow kidney disease progression in patients considered to be at high risk. For example, the AASK trial attempted aggressive BP control to slow renal progression in blacks [50]. For the overall population there was no renal function benefit with aggressive blood pressure control. On the other hand, Appel et al. [51] reported that aggressive lowering of blood pressure slowed renal progression in proteinuric AASK patients. Jafar et al. [52] examined 11 randomized controlled trials utilizing ACE inhibitors in nondiabetic subjects and found that aggressive BP control to systolic $110-129 \mathrm{~mm} \mathrm{Hg}$ appeared to benefit patients with over $1 \mathrm{~g}$ of daily proteinuria, while a systolic blood pressure below $110 \mathrm{~mm} \mathrm{Hg}$ was associated with a higher risk for kidney disease progression. Consistent with this, in the action to control cardiovascular risk in diabetes (ACCORD) study of high cardio- 
vascular risk type 2 diabetic patients, low levels of blood pressure were associated with both a decrease in proteinuria, and also with a lower eGFR [53].

\section{ACE/ARB Therapy}

Kent et al. [54] examined 11 randomized controlled trials using angiotensin-converting enzyme inhibitors (ACE) in nondiabetic kidney disease and found that patients with less than $500 \mathrm{mg}$ of proteinuria per day did not have a slowing of their renal trajectory with ACE treatment. In patients with type 2 diabetes and overt diabetic nephropathy, angiotensin-receptor blocker (ARB), irbesartan was effective at decreasing renal progression independent of the level of blood pressure reduction [55]. In the RENAAL study, use of losartan was associated with reduced BT from 5.2 to $4.4 \mathrm{ml} / \mathrm{min} /$ year $/ 1.73 \mathrm{~m}^{2}[56,57]$. Although it is generally accepted that ACE therapy slows renal progression in proteinuric patients, at least some of this 'benefit' may relate to increased tubular creatinine secretion [58].

\section{Proteinuria Reduction}

Proteinuria (which consists primarily of albumin) reduction may be the most important goal for slowing the loss of renal function. ACEs and ARBs produce similar reductions in proteinuria [59]. Since ACEs and ARBs can decrease proteinuria by different mechanisms, it was hypothesized that a combination of these drugs could produce an additive effect on proteinuria reduction and slowing of renal function decline. This led to the Ongoing Telmisartan Alone and in combination with Ramipril Global Endpoint Trial (ONTARGET) study in high vascular risk patients. This study found an increase in acute renal failure episodes and need for dialysis in nonproteinuric patients treated with the ACE and ARB combination [60]. In contrast to this, the Ramipril efficacy in nephropathy (REIN) study showed, for ACE therapy alone, that for each $1 \mathrm{~g}$ /day reduction in proteinuria, subsequent eGFR decline was slowed by $2 \mathrm{ml} / \mathrm{min} / 1.73 \mathrm{~m}^{2} /$ year [61].

In addition to single drug and combination therapy, up-titration of ACE or ARB therapy was studied in the renoprotection of optimal antiproteinuric doses (ROAD) study of benazepril, ACE and losartan, ARB. In this study, for those nondiabetic patients with a least $1 \mathrm{~g}$ proteinuria per 24-hour urine, up-titration of either ACE or $\mathrm{ARB}$ decreased proteinuria and rate of progression [62], possibly as a result of reversal of hyperfiltration. These drugs have been licensed for blood pressure lowering and not reduction of renal end points. These higher doses may be necessary in some cases to get the full benefit regarding slowing renal function loss.

The experience from several studies is that ACE or ARB therapy may produce an initial decline in eGFR and proteinuria. In the AASK study, decline in proteinuria in the first six months of therapy was predictive of the rate of decline in renal function in the following 3-6 years [40]. In the RENAAL study, the greater the acute fall in estimated eGFR in the first three months of treatment, the slower the long-term rate of decline in eGFR [63]. In fact, if one calculates renal trajectory from 3 to 6 months after starting a low-protein diet or ACE/ARB therapy, one may well get a slower decline in renal function than if initial eGFR is used.

\section{Diabetes Control}

In type 1 diabetics, better HGB A1C-related blood sugar control was associated with less loss of renal function [64], less need for RRT [64], and a slowing of a very rapid (10-12 $\mathrm{ml} / \mathrm{min} / 1.73 \mathrm{~m}^{2} /$ year) rate of renal function decline [66].

In the intensive blood glucose control and vascular outcomes type 2 diabetes (ADVANCE) study, tighter blood glucose control resulted in a $21 \%$ reduction in the risk of new CKD or worsening of CKD [67]. The ACCORD trial showed that aggressive glucose control delayed albuminuria in a type 2 diabetic population with cardiovascular risk factors [53], but target blood HGB A1C of 6 was associated with severe hypoglycemia and increased cardiovascular and total mortality [68].

\section{Alkali Therapy}

Several small observational studies and studies in animal models demonstrated a possible benefit of alkali therapy in slowing renal function decline early in the course of CKD and even in the absence of metabolic acidosis $[69,70]$. Alkali therapy may provide a dual benefit of decreasing protein catabolism as well as slowing of renal trajectory.

\section{Multidisciplinary Follow-Up}

In a study by Bayliss et al. [71], multidisciplinary renal clinic follow-up slowed the rate of basic trajectory decline from 2.5 to $1.2 \mathrm{ml} / \mathrm{min} / 1.73 \mathrm{~m}^{2} /$ year. In a second study, 
Barrett et al. [72] found no renal trajectory benefit from a nurse coordinated model of care, but this cohort largely had nonprogressive CKD.

\section{AKI and Renal Trajectory}

Inpatient AKI is associated with a more rapid decline in renal function and the development of ESRD [73]. This is especially true if the AKI episode required dialysis and if a patient had underlying CKD [74]. Ishani et al. [8] reported that the magnitude of serum creatinine increase after cardiac surgery was associated in a graded manner with the rate of decline in renal function after the AKI episode. As well, elderly patients with AKI and underlying CKD may show an increase in post-AKI rate of decline of eGFR [75].

AKI may be a frequent occurrence prior to dialysis initiation $[76,77]$. In a study of a US veteran population, O'Hare [pers. commun.] found that patients who initiate dialysis after a rapid loss of renal function were more likely to have an AKI episode and had a worse survival. Patients who initiate chronic dialysis after an AKI episode may do so at higher eGFR levels and this higher mortality in the post-AKI group may be part of the explanation for the association of higher eGFR at dialysis initiation and higher post-dialysis initiation mortality [78].

All of the reported studies to date on AKI involve patients who had hospitalization-related AKI. Recently, Rosansky et al. $[79,80]$ reported a high frequency of outpatient AKI episodes in patients who went on to dialysis and a higher frequency of outpatient AKI in patients who had a more rapid basic trajectory and higher proteinuria.

\section{Using Trajectory in Clinical Decisions}

Renal trajectory may be important in several areas of management of CKD. Patients with a slower trajectory (BT $<3 \mathrm{ml} / \mathrm{min} / 1.73 \mathrm{~m}^{2} /$ year) may require less intensive follow-up [81]. On the other hand, in one study, almost half of the patients had a nonlinear decline in renal function in the year prior to dialysis initiation [82]. A difference in rate of eGFR decline per year of $1 \mathrm{ml} / \mathrm{min} / 1.73 \mathrm{~m}^{2}$ can have a very powerful effect on the timeframe to start RRT. Different methodologies used to determine trajectory may give very different rates of decline [20]. Interestingly, the most recent published guidelines for dialysis initiation out of Europe emphasized the need to consider clinical symptomatology for dialysis initiation decisions but also included the notion of close observation for planned dialysis of patients with a renal trajectory of greater than $4 \mathrm{ml} / \mathrm{min} / 1.73 \mathrm{~m}^{2} /$ year, with the possibility of preemptive dialysis in this group [83].

Many studies have attempted to develop prediction models to determine which patients will have renal progression. These models use some of the factors for trajectory progression discussed above and others that were predictive in particular study populations. In the most recent study, Tangri et al. [84] developed and validated a tool to predict progression in patients with stage 3-5 CKD. The model uses eight variables: age, sex, eGFR, albuminuria, serum calcium, serum phosphate, serum bicarbonate, and serum albumin. These and other predictor models have several drawbacks. Firstly, they do not account for the reversible factors like decrease in proteinuria, discussed above, that may slow or reverse the decline in renal function. Second, these models do not attempt to separate patients who have stable renal function. Third, several studies have demonstrated that the rate of decline in renal function relates to mortality risk independent of baseline eGFR. For example, rates of decline of 3-4 ml/min $/ 1.73 \mathrm{~m}^{2} /$ year or greater have been shown to be predictive of mortality $[85,86]$. Also, AKI is associated with cardiovascular and all-cause mortality [87]. The vast majority of patients with CKD die before they require RRT [88]. Modeling to predict which patients will have rapid renal disease progression does not help determine whether the risk of death will supersede the need to prepare for RRT, a key consideration in management of CKD.

Several studies have attempted to identify which patients with CKD 3-5 were more likely to die prior to needing RRT. Demoulin et al. [89] studied 386 CKD 4 patients and found that after age 80 , the risk of death always exceeded the risk of ESRD. Similarly, O'Hare et al. [31], in a VA population followed for 3 years, found that for patients over 85 the risk of death always exceeded the risk of need for dialysis and for patients 65-84 years old this was true for patients with initial eGFR greater than $15 \mathrm{ml} / \mathrm{min} /$ $1.73 \mathrm{~m}^{2}$. On the other hand, in the AASK trial, where participants with diabetes or recent cardiovascular event were excluded and mean study entry age was 55 , patients were more likely to reach RRT than to die during the course of 11 years of follow-up [90]. Levin et al. [24] studied a CKD 4 population whose average eGFR decline was $2.65 \mathrm{ml} / \mathrm{min} / 1.73 \mathrm{~m}^{2} /$ year. Those patients with eGFR decline $>5 \mathrm{ml} / \mathrm{min} / 1.73 \mathrm{~m}^{2} /$ year had a $76 \%$ chance of starting dialysis during the 31-month average follow-up. Conway et al. [30] examined a CKD 4 population, over 75 
years old, and found that only in those patients with a decline over $4 \mathrm{ml} / \mathrm{min} / 1.73 \mathrm{~m}^{2} /$ year was dialysis prior to death required. In another study of patients with a median age of 80 and mean eGFR of $28.5 \mathrm{ml} / \mathrm{min} / 1.73 \mathrm{~m}^{2}$, only $20 \%$ had an eGFR change greater than $2 \mathrm{ml} / \mathrm{min} / 1.73$ $\mathrm{m}^{2} /$ year during a 31-month average follow-up [33], demonstrating the likely slower trajectory in elderly patients and likelihood of death prior to need for RRT.

In addition to age and CKD stage, proteinuria level may help determine who will require RRT. Conway et al. [30] found that for patients over 75 with less than $1 \mathrm{~g}$ of $24 \mathrm{~h}$ proteinuria, $90 \%$ avoided dialysis during an average follow-up of 10 years. Obi, in a Japanese cohort of CKD 3-5 patients followed for 3 years, found that for patients over 65 without proteinuria, none required RRT [91]. Adding primary etiology of renal disease is also helpful in predicting need for dialysis versus death. Generally, heavy proteinuric glomerular diseases, especially in a younger cohort, may require RRT before death.

Since AKI, especially AKI that required dialysis treatment, accelerates trajectory, these patients may require RRT. Nevertheless, the increased post-AKI mortality makes this another population that needs study of the competitive risk of death versus RRT, especially in the elderly.

In some octogenarians with stage 4 , or even stage 5 $\mathrm{CKD}$, slower trajectory and higher comorbidities and probability of death before RRT is required, makes placement of an arteriovenous (AV) access potentially unnecessary $[92,93]$. This issue needs further study, since these elderly patients are likely to require multiple access surgeries, to provide a working fistula or graft.

\section{Questions for Future Research}

From the current review there are clearly many unanswered questions regarding renal trajectory. These include: Does the decline in renal function accelerate at lower levels of renal function? Which AKI episodes, outpatient, inpatient, dialysis requiring, accelerate renal function decline? Are there patients who have recurrent outpatient or inpatient AKI episodes but have relatively stable renal function over extended periods of time? Can patients show a reversal of their decline in renal function with ACE/ARB or other therapies? Will this reversal only occur if patients are proteinuric and if the proteinuria reverses with $A C E / A R B$ therapies? Is the initial worsening of renal function with ACE/ARB use a good prognostic sign? Is a target $\mathrm{BP}$ of less than 110 beneficial in any group of CKD patients? Should a target BP of $110-129 \mathrm{~mm} \mathrm{Hg}$ only be used for proteinuric CKD patients? At what average level of HGBA1C do the benefits of slowing renal progression exceed possible harms? Can we develop models for predicting renal progression to determine the competitive risk for RRT versus death?

\section{Conclusions}

Change of renal function over time can vary considerably and may not show a linear decline or any decline over extended intervals. Both ACE and ARB therapy in proteinuric patients (at least $500 \mathrm{mg} / 24 \mathrm{~h}$ ) may slow renal function decline. Current observational studies support the notion that nonproteinuric patients with CKD will not benefit with a slower renal trajectory as a result of ACE or ARB or aggressive blood pressure treatment. The interaction between a patient's baseline trajectory and episodes of outpatient or inpatient AKI requires further exploration. Aggressive treatment of hyperglycemia and blood pressure may slow renal function decline, but may result in more harm than benefit in certain populations. Observational studies support the notion that renal trajectory in proteinuric hypertensive patients may benefit from aggressive BP lowering. Utilizing available published data, it appears that, especially in the elderly population with significant comorbidities and slow decline in renal function, the likelihood of death prior to need for RRT must be considered.

As more studies of renal trajectory become available clinicians may use this data to help decide: if and when an access for dialysis needs to be placed; which patients will likely succumb to a nonrenal failure death prior to needing dialysis; which patients may need more frequent renal clinic follow-up and when hospice and conservative management may be a more reasonable approach than a plan for dialysis therapy.

\section{Acknowledgements}

I would like to thank Connie Alice Griffin for her help with the manuscript and the librarian staff at the WJBD VA Hospital, Columbia, S.C., for their assistance obtaining the study references.

\section{Disclosure Statement}

None. 


\section{References}

$>1$ Hallan SI, Ritz E, Lydersen S, Romundstad S, $>14$ Fontseré N, Bonal J, Navarro M, et al: A comKvenlid K, Orth SR: Combining GFR and albuminuria to classify CKD improves prediction of ESRD. J Am Soc Nephrol 2009;20: 1069-1077.

-2 Froissart M, Rossert R, Jacquot, C, Paillard M, Houillier P: Predictive performance of the modification of diet in renal disease and Cockcroft-Gault equations for estimating renal function. J Am Soc Nephrol 2005;16: 763-773.

$>3$ Hois R, Bevc S, Ekart R, et al: Serum cystatin $\mathrm{C}$ as an endogenous marker of renal function in patients with mild to moderate impairment of kidney function. Nephrol Dial Transplant 2006;21:1855-1862.

4 Mitch WE, Walser M, Buffington GA, Lemann J Jr: A simple method of estimating progression of chronic renal failure. Lancet 1976;ii:1326-1328.

$\checkmark 5$ Foley RN, Murray AM, Li S, et al: Chronic kidney disease and the risk for cardiovascular disease, renal replacement, and death in the United States Medicare population, 1998 to 1999. J Am Soc Nephrol 2005;16:489-495.

6 Al-Aly Z, Zeringue A, Fu J, et al: Rate of kidney function decline associates with mortality. J Am Soc Nephrol 2010;21:1961-1969.

$>7$ Rifkin DE, Shlipak MG, Katz R: Rapid kidney function decline and mortality risk in older adults. Arch Intern Med 2008;168: 2212-2218.

$>8$ Ishani A, Nelson D, Clothier B, et al: The magnitude of acute serum creatinine increase after cardiac surgery and the risk of chronic kidney disease, progression of kidney disease, and death. Arch Intern Med 2011;171:226-233.

$\checkmark 9$ Murthy K, Stevens LA, Stark PC Levey AS: Variation in the serum creatinine assay calibration: a practical application to glomerular filtration rate estimation. Kidney Int 2005; 68:1884-1887.

$>10$ Coresh J Astor B: Kidney function in the elderly. Ann Intern Med 2006;145:299-301.

$>11$ Grootendorst DC, Michels WM, Richardson JD, et al; for the NECOSAD Study Group: The MDRD formula does not reflect GFR in ESRD patients. Nephrol Dial Transplant 2011;26:1932-1937.

12 Beddhu S, Samore MH, Roberts MS, et al: Creatinine production, nutrition, and glomerular filtration rate estimation. J Am Soc Nephrol 2003;14:1000-1005.

13 Stevens LA, Schmid CH, Greene T, et al: Comparative performance of the CKD epidemiology collaboration (CKD-EPI) and the modification of diet in renal disease (MDRD) study equations for estimating GFR levels above $60 \mathrm{ml} / \mathrm{min} / 1.73 \mathrm{~m}^{2}$. Am J Kidney Dis 2010;56:486-495. parison of prediction equations for estimating glomerular filtration rate in adult patients with chronic kidney disease stages $4-5$, effect of nutritional status and age. Nephron Clin Pract 2006;104:c160-c168.

15 Garcia-Naveiro R, Rodriguez-Carmona A, Pérez-Fontán M: Agreement between two routine methods of estimation of glomerular filtration rate in patients with advanced and terminal chronic renal failure. Clin Nephrol 2005;64:271-280.

16 Levey AS, Gassman JJ, Hall PM, Walker WG; for the MDRD Study Group: Assessing the progression of renal disease in clinical studies: effects of duration of follow-up and regression to the mean. J Am Soc Nephrol 1991; 1:1087-1094.

17 Eriksen BO, Ingebretsen OC: In chronic kidney disease staging the use of the chronicity criterion affects prognosis and the rate of progression. Kidney Int 2007;72:1242-1248.

18 Anderson AH: Screening for proteinuria: a tool for predicting rapid declines in kidney function? J Am Soc Nephrol 2011;22:15801583.

19 Fontseré N, Salinas I, Bonal J, et al: Are prediction equations for glomerular filtration rate useful for the long-term monitoring of type 2 diabetic patients? Nephrol Dial Transplant 2006;21:2152-2158.

20 Xie D, Joffe MM, Brunelli SM, et al: A comparison of change in measured and estimated glomerular filtration rate in patients with nondiabetic kidney disease. Clin J Am Soc Nephrol 2008;3:1332-1338.

21 Wang X, Lewis J, Appel L, et al: Validation of creatinine-based estimates of GFR when evaluating risk factors in longitudinal studies of kidney disease. J Am Soc Nephrol 2003; 14:1000-1005.

22 Lewis J, Greene T, Appel L, et al; for the AASK Study Group; A comparison of iothalamate-GFR and serum creatinine-based outcomes: acceleration in the rate of GFR decline in the African-American study of kidney disease and hypertension. J Am Soc Nephrol 2004;15, 3175-3183.

23 Clark WF, Macnab JJ, Sontrop JM, et al: Dipstick proteinuria as a screening strategy to identify rapid renal decline. J Am Soc Nephrol 2011;22:1729-1736.

24 Levin A, Djurdjie O, Beaulieu M, Er L: Variability and risk factors for kidney disease progression and death following attainment of stage $4 \mathrm{CKD}$ in a referred cohort. Am J Kidney Dis 2008;52:661-671.

25 Eriksen BO Ingebretsen OC: The progression of chronic kidney disease: a 10 -year population-based study of the effects of gender and age. Kidney Int 2006;69:375-382.
26 Rottey S, Vanholder R, De Schoenmakere G, Lameire N: Progression of renal failure in patients with compromised renal function is not always present: evaluation of underlying disease. Clin Nephrol 2000;54:1-10.

27 Hunsickler LG, Adler S, Caggiula A, et al: Predictors of the progression of renal disease in the modification of diet in renal disease study. Kidney Int 1997;51:1908-1919.

28 Perkins RM, Bucalord JD, Kirchner HL, Ashouian N, Hartle JE, Yahya T: GFR decline and mortality risk among patients with chronic kidney disease. Clin J Am Soc Nephrol 2011;6:1879-1886.

29 Lindeman RD, Tobin J, Shock NW: Longitudinal studies on the rate of decline in renal function with age. J Am Geriatr Soc 1985;33: 278 .

30 Conway B, Webster A, Ramsay G, et al: Predicting mortality and uptake of renal replacement therapy in patients with stage 4 chronic kidney disease. Nephrol Dial Transplant 2009;24:1930-1937.

31 O'Hare AM, Choi AI, Bertenthal D, et al: Age affects outcomes in chronic kidney disease. J Am Soc Nephrol 2007; 18:2758-2765.

32 Evan M, Fryzek JP, Elinder C-G, et al: The natural history of chronic renal failure: results from and unselected, populationbased, inception cohort in Sweden. Am J Kidney Dis 2005;46:863-870.

-33 John R, Webb M, Young A, Stevens PE: Unreferred chronic kidney disease: a longitudinal study. Am J Kidney Dis 2004;43:825-835.

34 Imai E, Horio M, Yamagata K, et al: Slower decline of glomerular filtration rate in the Japanese general population: a longitudinal 10-year follow-up study. Hypertens Res 2008;31:433-441.

-35 Neugarten J, Acharya A, Silbiger SR: Effect of gender on the progression of nondiabetic renal disease: a meta-analysis. J Am Soc Nephrol 2000;11:319-329.

36 Jafar TH, Schmid CH, Stark PC, et al: The rate of progression of renal disease may not be slower in women compared with men: a patient-level meta-analysis. Nephrol Dial Transplant 2003;18:2047-2053.

37 Levey AS, de Jong PE, Coresh J, et al: The definition, classification, and prognosis of chronic kidney disease: a KDIGO controversies conference report. Kidney Int 2011;80: 17-28.

38 Gansevoort RT, Matsushita K, van der Velde $M$, et al: Lower estimated GFR and higher albuminuria are associated with adverse kidney outcomes. A collaborative meta-analysis of general and high-risk population cohorts. Kidney Int 2011;80:93-104.

39 Hemmelgarn BR, Manns BJ, Lloyd A, et al: Relation between kidney function, proteinuria, and adverse outcomes. JAMA 2010;303: 423-429. 
-40 Lea J, Greene T, Herbert L, et al: The relationship between magnitude of proteinuria reductiona and risk of end-stage renal disease. Arch Intern Med 2005;165:947-953.

-41 Keane WF, Brenner BM, de Zeeuw D, et al: The risk of developing end-stage renal disease in patients with type 2 diabetes and nephropathy: the RENAAL study. Kidney Int 2003;63:1499-1507.

-42 Peralta CA, Katz R, Deboer I, et al: Racial and ethnic differences in kidney function decline among persons without chronic kidney disease. J Am Soc Nephrol 2011;22:1327-1334.

-43 Barbour SJ, Schachter M, Er L, Djurdjev O, Levin A: A systematic review of ethnic differences in the rate of renal progression in CKD patients. Nephrol Dial Transplant 2010;25:2422-2430.

-44 Klag MJ, Whelton PK, Randall BL, Neaton JD, Brancati FL, Stamler J: End-stage renal disease in African-American and white men. JAMA 1997;277:1293-1298.

-45 McClellan WM, Warnock DG, Judd S, et al: Albuminuria and racial disparities in the risk for ESRD. J Am Soc Nephrol 2011;22: 1721-1728.

-46 Menon V, Kopple JD, Wang X, et al: Effect of a very low-protein diet on outcomes: longterm follow-up of the modification of diet in renal disease (MDRD) study. Am J Kidney Dis 2009;53:208-217.

47 Halbesma N, Bakker SJ, Jansen DF, et al: High protein intake associates with cardiovascular events but not with loss of renal function. J Am Soc Nephrol 2009;20:17971804.

48 Hallan SI Orth SR: Smoking is a risk factor in the progression to kidney failure. Kidney Int 2011;80:516-523.

49 Rosansky SJ, Hoover D, King L Gibson J: The association of blood pressure levels and change in renal function in hypertensive and non-hypertensive subjects. Arch Int Med 1990;150:2073-2076.

50 Wright Jr JT, Bakris G, Greene T, et al: Effect of blood pressure lowering and antihypertensive drug class on progression of hypertensive kidney disease. JAMA 2002;288: 2421-2431.

-51 Appel LJ, Wright JT, Greene T, et al: Intensive blood-pressure control in hypertensive chronic kidney disease. N Engl J Med 2010; 363:918-929.

52 Jafar TH, Stark PC, Schmid CH, et al: Progression of chronic kidney disease: the role of blood pressure control, proteinuria, and angiotensin-converting enzyme inhibition, a patient-level meta-analysis. Ann Intern Med 2003;139:244-252.

53 ACCORD Study Group: Effects of intensive blood-pressure control in type 2 diabetes. $\mathrm{N}$ Engl J Med 2008;358:2545-2559.
54 Kent DM, Jafar TH, Hayward RA, et al: Progression risk, urinary protein excretion, and treatment effects of angiotensin-converting enzyme inhibitors in nondiabetic kidney disease. J Am Soc Nephrol 2007;18:19591965.

55 Lewis EJ, Hunsicker LG, Clarke WR, et al: Renoprotective effect of the angiotensin-receptor antagonist irbesartan in patients with nephropathy due to type 2 diabetes. $\mathrm{N}$ Engl J Med 2001;345:851-860.

56 Brenner BM, Cooper ME, de Zeeuw D, et al: Effects of losartan on renal and cardiovascular outcomes in patients with type 2 diabetes and nephropathy. N Engl J Med 2001;345: 861-869.

57 Bakris GL: Slowing nephropathy progression: focus on proteinuria reduction. Clin J Am Soc Nephrol 2008;3:S3-S10.

58 Thomas MC, Jerums G, Salamandris C, MacIssac R, Panagiotopoulos S, Cooper ME, MDNSG Study Group: Increased tubular organic ion clearance following chronic ACE inhibition in patients with type 1 diabetes. Kidney Int 2005;67:2494-2499.

-59 Kunz R, Friedrich C, Wolbers M, Mann JFE: Meta-analysis: effects of monotherapy and combination therapy with inhibitors of the renin-angiotensin system on proteinuria in renal disease. Ann Intern Med 2008; 148:30 48.

60 Mann JFE, Schmieder RE, McQueen M, et al: Renal outcomes with telmisartan, ramipril, or both, in people at high vascular risk (the ONTARGET study): a multicentre, randomised, double-blind, controlled trial. Lancet 2008;372:547-553.

61 Ruggenenti P, Perna A, Remuzzi G; on behalf of the investigators of the GISEN group: Retarding progression of chronic renal disease: the neglected issue of residual proteinuria. Kidney Int 2003;63:2254-2261.

62 Hou FF, Xie D, Zhang X, et al: Renoprotection of optimal antiproteinuric doses (ROAD) study: a randomized controlled study of benazepril and losartan in chronic renal insufficiency. J Am Soc Nephrol 2007; 18:1889-1898.

63 Holtkamp FA, de Zeeuw D, Thomas MC, et al: An acute fall in estimated glomerular filtration rate during treatment with losartan predicts a slower decrease in long-term renal function. Kidney Int 2011;80:282-287.

64 De Boer IH, Sun W, Cleary PA, et al: Intensive diabetes therapy and glomerular filtration rate in type 1 diabetes. $\mathrm{N}$ Engl J Med 2011;365:2366-2376.

65 Forsblom C, Harjutsalo V, Thorn LM: Compteting-risk analysis of ESRD and death among patients with type 1 diabetes and macroalbuminuria. J Am Soc Nephrol 2011; $22: 537-544$.
66 Hovind P, Rossing P, Tarnow L, Smidt UM, Parving HH: Progression of diabetic nephropathy. Kidney Int 2001;59:702-709.

67 The ADVANCE Collaborative Group: Intensive blood glucose control and vascular outcomes in patients with type 2 diabetes. $\mathrm{N}$ Engl J Med 2008;358:2560-2572.

68 Ismail-Beigi F, Craven T, Banerji MA, et al: Effect of intensive treatment of hyperglycaemia on microvascular outcomes in type 2 diabetes: an analysis of the ACCORD randomised trial. Lancet 2010;376:419-430.

69 Sahni V, Rosa RM, Batlle D: Potential benefits of alkali therapy to prevent GFR loss: time for a palatable 'solution' for the management of CKD. Kidney Int 2010;78:10651067.

70 De Brito-Ashurst I, Varagunam M, Raftery MJ, Yagoob MM: Bicarbonate supplementation slows progression of $\mathrm{CDK}$ and improves nutritional status. J Am Soc Nephrol 2009; 20:2075-2084.

-71 Bayliss EA, Bhardwaja B, Ross C, Beck A, Lanese DM: Multidisciplinary team care may slow the rate of decline in renal function. Clin J Am Soc Nephrol 2011;6:704-710.

72 Barrett BJ, Garg AX, Goeree R, et al: A nursecoordinated model of care versus usual care for stage 3/4 chronic kidney disease in the community: a randomized controlled trail. Clin J Am Soc Nephrol 2011;6:1241-1247.

73 Wu V, Huang T-M, Lai C-F, et al: Acute-onchronic kidney injury at hospital discharge is associated with long-term dialysis and mortality. Kidney Int 2011;80:1222-1230.

-74 Hsu CY, Ordoñez JD, Chertow GM, Fan D, McCulloch CE, Go AS: The risk of acute renal failure in patients with chronic kidney disease. Kidney Int 2008;74:101-107.

-75 Ishani A, Xue JL, Himmelfarb J, et al: Acute kidney injury increases risk of ESRD among elderly. J Am Soc Nephrol 2009;20:223-228.

76 Onuigbo MAC: Syndrome of rapid-onset end-stage renal disease: a new unrecognized pattern of CKD progression to ESRD. Renal Failure 2010;32:964-958.

77 Seabra VF, Balk EM, Liangos O, Sosa MA, Cendoroglo M, Jaber BL: Timing of renal replacement therapy initiation in acute renal failure: a meta-analysis. Am J Kidney Dis 2008;52:272-284.

78 Rosansky SJ, Glassock RJ, Clark WF: Early start of dialysis: a critical review. Clin J Am Soc Nephrol 2011;6:1222-1228.

79 Rosansky SJ, Hardin JW, Richards F, et al: Relationship between outpatient 'AKI', proteinuria, diagnosis diabetes, race and rate of decline in renal function, nine years prior to dialysis initiation. 2011; http://www.asn-online.org.

80 Rosansky SJ, Hardin JW, Richards F, et al: The relationship of urine proteinuria to outpatient 'AKI' and renal progression. 2011; http://www.asn-online.org. 
81 Jones C, Roderick P, Harris S, Rogerson M: Decline in kidney function before and after nephrology referral and the effect on survival in moderate to advanced chronic kidney disease. Nephrol Dial Transplant 2006;21: 2133-2143.

82 Ambrogi V, Thilly N, Boini S, Virion J-M: Patterns and predictors of kidney function decline in the last year prior to dialsys. Nephron Clin Pract 2009;111:c95-c101.

83 Tattersall J, Dekker F, Heimbürger O: When to start dialysis: updated guidance following publication of the initiating dialysis early and late (IDEAL) study. Nephrol Dial Transplant 2011;26:2082-2086.

84 Tangri NA, Stevens LA, Griffith J: A predictive model for progression of chronic kidney disease to kidney failure. JAMA 2011;305: 1553-1559.
85 Shlipak MG, Katz R, Kestenbaum B, et al: Rapid decline of kidney function increases cardiovascular risk in the elderly. J Am Soc Nephrol 2009;20:2625-2630.

86 Matsushita K, Selvin E, Bash LD, Franceschini N, Astor BC, Coresh J: Change in estimated GFR associates with coronary heart disease and mortality. Clin J Am Soc Nephrol 2009;20:2617-2624.

87 Hsu CY, Chertow GM, McCulloch CE, Fan D, Ordoñez Go AS: Nonrecovery of kidney function and death after acute on chronic renal failure. Clin J Am Soc Nephrol 2009;4: 891-898.

88 Jaar BG, Khatib R, Plantinga L, Boulware, LE, Powe NR: Principles of screening for chronic kidney disease. Clin J Am Soc Nephrol 2008;3:601-609.

89 Demoulin N, Beguin C, Labriola L, Jadoul M: Preparing renal replacement therapy in stage $4 \mathrm{CKD}$ patients referred to nephrologists: a difficult balance between futility and insufficiency. A cohort study of 386 patients followed in Brussels. Nephrol Dial Transplant 2011;26:220-226.
-90 Alves TP, Wang X, Wright JT Jr, et al: Rate of ESRD exceeds mortality among African Americans with hypertensive nephrosclerosis. J Am Soc Nephrol 2010;21:1361-1369.

91 Obi Y, Kimura R, Nagasawa Y, et al: Impact of age and overt proteinuria on outcomes of stage 3 to 5 chronic kidney disease in a referred cohort. Clin J Am Nephrol 2010;5: 1558-1565.

92 O'Hare AM, Bertenthal D, Walter LC, et al: When to refer patients with chronic kidney disease for vascular access surgery: should age be a consideration? Kidney Int 2007;71: 555-561.

93 Vachharajani TJ, Moossavi S, Jordan JR, Vachharajani V, Freedman BI, Burkart JM: Re-evaluating the fistula first initiative in octogenarians on hemodialysis. Clin J Am Soc Nephrol 2011;6:1663-1667. 